\title{
Memória do holocausto: uma categoria literária do testemunho
}

\author{
Memory of the holocaust: a literary category of testimony
}

\begin{abstract}
Alba OImi
Doutora em Literatura Comparada pela UFRGS. Ex-docente da UNISC, hoje aposentada
\end{abstract}

Resumo:Este artigo é resultado de uma profunda reflexão que busca enfatizar a importância e o alcance multidisciplinar e/ou transdisciplinar da literatura oriunda dos sobreviventes do Holocausto tanto em termos de memória pessoal como de memória histórica. Além disso, pretende também enfatizar a necessidade de buscar respostas aos questionamentos de ordem ética e política que, na pós-modernidade, ainda não foram completamente desvendados, buscando incentivar uma mais ampla discussão do tema também no Brasil onde pouco se trata do tema. Por esse motivo, o texto, previamente publicado em 2009, pela Revista Espéculo, da Universidad Complutense de Madrid, foi revisto e enriquecido dentro da proposta da Revista Signo que, ao celebrar os seus 40 anos de existência, optou por oferecer ao seu público as releituras de textos anteriormente publicados.

Palavras-chave:Holocausto. Literatura de testemunho. História. Política.

\begin{abstract}
This article is the result of a deep reflection trying to emphasize the importance and the multidisciplinary or trans-disciplinary attainment of literature written by survivors of Holocaust in terms of personal memory as well as historical memory. Furthermore we want to stress the need of looking for responses to the ethical and political questions that were not yet fully revealed in post-modernity, trying to motivate a wilder discussion of the theme also in Brazil, where the issue is seldom brought into question. For that reason this essay, previously edited by Revista Espéculo from Universidad Complutense de Madrid in 2009, has been revised and expanded according to the suggestion of Revista Signo that, as celebrating 40 years of existence, decided to offer the readers a new interpretation of essays previously published.
\end{abstract}

Keywords: Holocaust. Witness literature. History. Politics. 


\section{Introdução}

Há 70 anos, no dia 27 de janeiro de 1945, os campos de concentração nazistas de Auschwitz e Birkenau foram abertos e os restantes prisioneiros libertados pelas tropas soviéticas. Lá se encontravam 7.000 prisioneiros ainda vivos. Já a partir do dia 18 de janeiro, os demais que haviam sobrevivido ao massacre haviam sido evacuados e obrigados a uma longa marcha, a pé, no gelo do inverno polonês, na direção de Bergen-Belsen. Ao longo dessa marcha cruel, milhares perderam a vida pelo frio, pela fome, ou foram sumariamente trucidados pelos soldados do Reich.

Quando o Exército Soviético giá se encontrava em territorio polonês, a pouca distância de Cracóvia, as autoridades nazistas apressaram-se a evacuar o campo de concentração de AuschwitzBirkenau e os demais sub-campos das redondezas, para tentar apagar as evidências.

Em 17 de janeiro, o número total dos prisioneiros nos campos de Auschwitz-Birkenau e nos sub-campos de Babitz, Budy e Plawny era de 31.894. Pelos planos nazistas, partiriam somente aqueles prisioneiros que estivessem em condições de enfrentar uma longa marcha a pé, no frio extremo do inverno polonês. Todavia, durante a chamada feita pelos comandantes do Lager, responderam afirmativamente vários prisioneiros muito debilitados ou doentes, assim como mulheres e crianças. Muitos deles estavam certos de que se ficassem no campo seriam exterminados pelas SS em fuga.

No mesmo dia histórico, o comandante de Auschwitz, o SS-Sturmbhanführer Richard Baer, ordenou a organização das filas dos presos. Como responsáveis pela evacuação foram escolhidos dois entre os mais ferozes e sanguinários oficiais do Lager: o SS-oberscharführer Wilhelm Boger e seu vice Oswald Kaduk. A ordem peremptória era de matar todos os prisioneiros que tivessem tentado fugir ao longo do processo de evacuação.

No dia seguinte, 18 de janeiro, começa a evacuação final de Auschwitz-Birkenau. Antes foram organizadas as filas de mulheres e crianças.
Seguindo, vinham os homens, enquanto alguns grupos de prisioneiros escolhidos pelas SS receberam a tarefa de começar a demolir os fornos crematórios.

À noite, uma coluna sem fim de prisioneiros, aos quais se juntaram os presos do campo de trabalhos forçados de Monowice, marchava para o Oeste, na direção da Silésia, para depois serem encaminhados às ferrovias.

Já nas primeiras horas da marcha, 172 caíram e foram sepultados nos barrancos da estrada, em fossas comuns. Os prisioneiros exaustos se arrastavam na neve, e quem parava era morto no mesmo lugar pelos SS que os acompanhavam. Morreram às centenas poucas horas antes da libertação, após ter resistido longamente ao horror da vida no Lager. Calcula-se que somente na área de Auschwitz, nos primeiros dias da evacuação, tenham morrido mais de 3.000 prisioneiros a um passo da liberdade.

Enquanto o campo de Auschwitz era esvaziado, as tropas nazistas iniciaram a destruição das provas materiais da carneficina. Em 20 de janeiro explodem os crematórios II e III. Seis dias depois é a vez do crematório $V$, até então ainda em condições operativas. A seguir, foi a vez do conjunto de armazéns conhecido como "Kanada II", onde eram estocados todos os bens arrancados dos prisioneiros, desde roupas até cabelos, dentes de ouro e outros pertences de toda natureza.

Ainda permaneciam 9.000 prisioneiros no campo principal de Auschwitz (Stammlager Auschwitz 1) e Birkenau (Auschwitz II): os algozes intencionavam eliminar a maior parte deles antes da chegada do Exército Soviético. Somente a pressa dos nazistas conseguiu que a maior parte dos prisioneiros que ainda permaneciam no campo fosse poupada, com a exceção de aproximadamente 700 prisioneiros judeus trucidados nos sub-campos poucas horas antes da chegada dos soldados soviéticos na data histórica de 27 de janeiro de 1945 que o mundo civilizado acaba de celebrar neste ano de 2015. Essa data enseja, portanto, mais um repensamento e mais uma releitura dos acontencimentos que abalaram o 
século XX, resumidos na dolorosa palavra "Holocausto".

\section{Testemunho e Memória: a estrutura da narrativa do Holocausto}

E então, que memória do tempo do totalitarismo estamos construindo no tempo da democracia? Trata-se de fazer a arqueologia do nazismo ou a genealogia da democracia?De enfatizar o mal absoluto que a democracia venceu ou arquivou, ou o seu espectro que na democracia ainda pode materializar-se? Ida Dominjianni

Definida há tempo, na França, com cátedras universitárias nos Estados Unidos e na Itália, a narrativa do Holocausto é lamentavelmente pouco estudada no Brasil, onde encontramos escassas traduções das obras de autores sobreviventes dos campos nazistas de extermínio, embora a importância dessa literatura seja relevante também para a América Latina, pelo fato de ela propiciar a possibilidade de produzir interrogativos de ordem ética, moral e histórica irrenunciáveis. Sem deixar de recordar que o Brasil foi refúgio ilegal de diversos criminais nazistas.

Em primeiro lugar é necessário definir os campos, a fim de fazer uma breve historiografia da literatura do Holocausto, por ser esta um conglomerado amplo e extremamente complexo, sem, no entanto, cair no redutivismo. Stefano Zampieri (2004) ${ }^{1}$ sugere a imagem do arquipélago ao invés de ilha, isto é, um espaço perfeitamente delimitado por confins bem precisos. Para ele, $A$ literatura do Lager é um conjunto de espaços muito articulado, justamente, um arquipélago.

Zampieri aborda basicamente a literatura do sobrevivente-escritor, isto é, do testemunho real, evitando falar de aspectos tão interessantes quanto o retorno, a re-inserção familiar e social, as memórias dos guetos, os diários, as cartas e o cinema que relaciona a ficção ao campo de Auschwitz, realizado por parte de roteiristas e diretores cinematográficos que não viveram essa experiência, com exceção,

\footnotetext{
${ }^{1}$ Ver, do mesmo autor, II flauto d'osso: Lager e letteratura. Firenze: La Giuntina, 1996.
}

talvez, de Roman Polanski, diretor do festejado filme O pianista e também sobrevivente.

De nossa parte, procurou-se, sobretudo, evidenciar os amplos campos de investigação que este tipo de literatura pode ensejar, propiciando a investigação transdisciplinar, por ser ela "complementar à abordagem disciplinar; ela faz emergir do confronto das disciplinas novos dados que as articulam entre si [...]" (NICOLESCU, 2001, p.160).

Trata-se de uma questão ampla e delicada porque envolve interesses e disciplinas variados, mas também saltos geracionais: da primeira geração das testemunhas à segunda e à terceira, esta constituindo uma geração que vê o Holocausto em terceira mão. São os descendentes das vítimas que começam a falar num outro tempo e noutro contexto sócio-cultural e político.

O grande problema, em relação aos jovens de hoje, é que, após 70 anos, mesmo diante de uma sensibilidade e de uma curiosidade ainda relativamente acesa, o evento pode transformar-se numa espécie de "imagem virtual, colocada num ambiente que não possui consistência real, onde tudo está apenas na superfície, sem substância [...]" (ZAMPIERI, 2004, p.67) ${ }^{2}$. Sem considerarmos o trabalho nefasto dos "revisionistas" e/ou "negacionistas" como Arthur Butz, Ernst Nolte, Bardèche ou Rassinier, entre muitos outros, que pretendem negar o Holocausto e o testemunho de suas vítimas, como se a história pudesse ser apagada com uma esponja de descrença e desconfiança. Mas aqui caberia outro longo ensaio.

\section{A literatura do Lager e suas fases}

Zampieri propõe a "Literatura do Lager" (p. 74) como sinônimo de testemunho, testemunho que só o escritor sobrevivente pode registrar por escrito. E, a partir dessa delimitação, ele propõe também a delineação de três fases importantes.

\footnotetext{
“[...] immagine virtuale, cioè una immagine in qualche maniera collocata in un mondo che non ha consistenza reale, dove tutto è ugualmente superficie, senza sostanza, senza realtà [....]". Todas as traduções dos originais aqui realizadas são de minha responsabilidade.
} 
A primeira, imediatamente após o fim da II Guerra Mundial, nos meados dos anos 40, produziu obras, em sua maioria, impressas por pequenos editores ou até por tipografias, dirigidas a um pequeno público representado por amigos, vizinhos e parentes dos que voltaram dos campos. Justamente aquele público que tinha grande dificuldade em aceitar esses testemunhos por várias razões, desde 0 desejo de virar as páginas de um momento histórico candente, até o desejo de não ser envolvidos emocionalmente num evento tão espantoso.

As urgências políticas e sociais eram também uma grande razão para dar menor importância a essa literatura: era a época do pós-guerra e tudo tinha que ser reconstruído, refeito, re-organizado. Nesse contexto, avalia Zampieri, deu-se preferência ao mito do sobrevivente ao invés do mito da vítima (id., ibid.). Pouco a pouco surgiu inclusive um certo sentimento de culpa por parte dos sobreviventes, justamente por terem sobrevivido, que determinou a política do silêncio que abarca o período entre a imediata libertação dos campos até meados da década de 50, cerca de uma década.

Havia também uma grande dificuldade em compreender o sentido do anti-semitismo muito difundido na Europa desde a Antigüidade e que foi uma das muitas causas do genocídio: "Foi o milenar antijudaísmo cristão o habitat favorável para o surgimento e o desenvolvimento do anti-semitismo moderno? Contribuiu a antiga inimizade para tornar os cristãos incapazes ou fracos demais para reagirem firmemente contra o ódio racial?," Brocchieri (2005). Acrescentaríamos mais uma pergunta: por que nem o Vaticano nem a Cruz Vermelha e muito menos as nações livres se levantaram para impedir o massacre? Embora se saiba que sacerdotes católicos salvaram a vida de cerca de 4.000 judeus (perdendo sua vida por isso) e que Pio XII tenha auxiliado nessa luta.

De fato, para compreender a obstinada oposição aos judeus, não se pode ignorar, como

\footnotetext{
${ }^{3}$ "Il millenario antigiudaismo cristiano è stato il favorevole habitat per la nascita e lo sviluppo dell 'antisemitismo moderno? L'antica inimicizia antiebraica ha contribuito a rendere i cristiani incapaci o deboli nel reagire fermamente all'odio razziale?"
}

salienta Piero Stefani (2004), "o álibi do deicídio", isto é, o relevante e cruel papel histórico que a imputação de "deicídio" representou contra o povo de Israel. Provavelmente foi esse mito selvagem e infundado que alimentou um longo processo de desprezo, ódio e perseguição. Stefani propõe uma análise da própria idéia de antijudaísmo a partir do surgimento da Igreja Católica e da formação de sua identidade. Descartando o termo anti-semitismo, o autor estuda o percurso do "antijudaísmo" em todas as variantes utilizadas ao longo de dois mil anos. De qualquer maneira, sejam quais forem as razões da perseguição aos judeus, particularmente aquela perpetrada pelos nazistas, é certo que a tragédia alimentou uma abundante literatura que continua crescendo até o presente.

Voltando à primeira fase, da metade dos anos 40 em diante, podemos citar o fundador dessa literatura, Primo Levi, brilhante químico italiano, com Se questo è un uomo (1958), morto (presumidamente) suicida em 1987, em parte pelo complexo de culpa comum a muitos sovreviventes (por que eu não morri com os outros?), em parte pela pouca compreensão da família que, talvez, duvidasse dos indizíveis fatos que ele narravas sobre sua estada nos campos. O texto não foi escrito para acusar os culpados, mas como testemunho de um trágico evento histórico. O próprio Levi afirmava che "o livro havia nascido", já no Lager, per uma necessidade irrenunciável de contar aos outros, de fazer os outros partícipes dos fatos, para tentar explicar de alguma forma a incrível verdade dos campos nazistas. Citamos ainda Robert Antelme, autor de A espécie humana (2013), livro que esperou 66 anos para ser traduzido em português e publicado recentemente no Brasil pela Record. A primeira edição francesa data de 1947. Aqui também se percebe a urgência da narrativa tentando objetivar a terrivel experiência, porém com tom já decantado, embora mais eficaz de qualquer grito de denúncia; percebe-se a atenção quase antropológica do prisioneiro político (ele não era judeu), com aquilo que acontece a seu redor. E ainda citamos David Rousset, autor de L'univers concentrationnaire (1946) 
e, sobretudo, de Les jours de notre mort (2005), um grande romance (de sub-fundo ficcional) e uma narrativa memorialista de valor extraordinário e grande profundidade.

Na Europa, e mais tarde nos Estados Unidos, inclusive as publicações das mulheres sobreviventes são abundantes, como, por exemplo, II fumo di Birkenau (MILLU, primeira edição em 1947), com várias re-edições posteriores e traduções também. Trata-se de um entre os muitos testemunhos poderosos - e/ou silenciosos - de mulheres sobreviventes ou mortas em Auschwitz, e cujas memórias foram recolhidas caridosa e carinhosamente pelas companheiras que conseguiram sobreviver, quando não são diários encontrados muito depois da morte das vítimas. 0 livro, que traz o prefácio assinado por Primo Levi, representa um dos mais intensos testemunhos europeus sobre o Lager feminino de AuschwitzBirkenau, certamente a mais tocante entre as narrativas italianas, no qual a jornalista e escritora descreve a vida minimal e desperada das prisioneiras, constantemente circundadas pelas chaminés dos fornos crematórios que não deixam espaço à esperança.

Nos quinze anos seguintes, quando a Europa readquire sua estabilidade, quando começa o boom econômico, as pessoas estão querendo esquecer os tempos difíceis. Foi nessa segunda fase, quando provavelmente foi construída uma proteção capaz de defender as pessoas da irrupção das memórias, quando também surgiu um clima mais propício à escuta, que os leitores se tornaram mais disponíveis a ouvir o que os sobreviventes tinham a dizer, ou "precisavam" dizer.

Estamos em meados dos anos 50, quando surge uma obra emblemática que já faz parte do cânone que está se consolidando. Trata-se de $A$ noite, de Elie Wiesel, prêmio Nobel da Paz em 1986, que escreve o livro dez anos após sua volta de Auschwitz, onde fora internado com toda a família. A necessidade de escrever sua história brota de forma incoercível em sua língua materna, em yiddish, mas o livro é publicado numa raríssima edição na Argentina, em 1956, uma primeira versão cujo título era $Y$ el mundo callaba, publicada pela Unión Israelita Polaca. Somente em 1958, Wiesel publicaria La nuit, escrita em francês, na "língua da liberdade", nas palavras de Wiesel, e porque agora ele teria um público leitor (hoje, a obra é traduzida em mais de 30 línguas). Trata-se de um livro que precisa ser lido em primeiro lugar dentro de sua vasta produção, porque, na época, como ele próprio afirma, qualquer tipo de opção era possível: o suicídio, a loucura, a vingança, a ação política, o ódio ou a amizade. A fé, a descrença, o ateísmo, a recusa do humano, o desespero. Em cada um de seus livros, Wiesel explorou um desses aspectos, embora todas as histórias contadas não passem de uma só que ele construiu em círculos concêntricos, e o centro está justamente em $A$ noite.

A terceira fase desse percurso é a da grande virada dos anos 60. O processo Eichmann (1961) age como mola propulsora que se torna uma grande "psicoterapia de grupo, estabelecendo o novo papel do testemunho, uma nova dignidade das vítimas que são chamadas como protagonistas e cujas palavras agora têm valor, constituindo um legítimo ato público de acusação pública com a qual é preciso lidar". ${ }^{4}$ (ZAMPIERI, 2004, p.70).

Um outro elemento de importância não menor é representado pelos acontecimentos históricos em Israel, isto é, os eventos dramáticos da Guerra dos Seis Dias (1967). Um período no qual, de alguma forma, o hebraísmo parece correr perigo e, portanto, é necessário repensar a Shoah.

Esses dados serão de importância fundamental, porque irão mudar a intenção do sobrevivente escritor, modificando a disponibilidade do público para a escuta. Vale a pena citar, aqui, apenas como exemplo, embora haja uma literatura muito abundante nessa fase, a festejada obra de Jorge Semprún, El largo viaje (que teve uma primeira edição em francês em 1963). É o testemunho da deportação sofrida pelo intelectual espanhol para

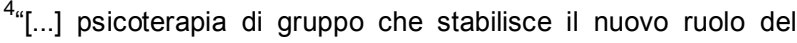
testimone, una nuova dignità della vittima che è chiamata ad essere protagonista, le sue parole hanno valore, costituiscono un vero e proprio atto di accusa .pubblico su cui ci si deve misurare."
} 
Buchenwald, embora ele não fosse judeu: era apenas um militante comunista na Espanha franquista e era pouco mais que adolescente na época de sua deportação. Semprún escreve o livro somente quase duas décadas depois de sua libertação porque era preciso fazê-lo.

Em sua autobiografia, intitulada All rivers run to sea $^{5}$, Elie Wiesel afirma que esse título significa que o mar das lembranças continua recebendo alimento. Essa afirmativa confirma o fato de que muitas testemunhas, inclusive de idade já avançada, voltam ao relato escrito e publicam suas memórias, como explicita, por exemplo, a opera omnia de Edith Bruck. Em Signora Auschwitz: il dono della parola (1999) a dor da memória é narrada com grande paixão, juntamente com 0 desespero diante da incredulidade dos outros: é preciso um enorme heroísmo para narrar o horror vivenciado. Podemos citar ainda a obra de Elisa Springer, a qual voltaremos mais adiante, entre muitas outras. Tudo isso revela uma legítima ânsia de testemunho, mas também revela que o leitor mudou, por isso essa literatura precisa "dizer" de forma diferente, sem saturar, sem sobrecarregar, sem desgastar, apenas fazer compreender, sem criar uma possível rejeição por parte do público.

Já no primeiro volume de sua autobiografia, Wiesel volta ao momento em que brotou nele, com enorme vigor, o desejo da escritura, e ele o descreve como febril, como se the faltasse 0 ar, ele escreve apressadamente, para impedir que os mortos morram, para justificar (e perdoar) a sobrevivência dele. Escreve para falar aos que desapareceram. Enquanto se dirige aos mortos, eles continuarão vivos em sua memória (p. 278).

Wiesel vê a memória como a forma de reviver um passado, iluminar rostos e eventos de uma luz branca e preta, dizer não à areia que cobre as palavras, dizer não ao esquecimento, à morte. Eis por que, aos 65 anos, Elie Wiesel decide escrever suas memórias, refazendo o percurso de sua vida, desde a infância feliz em Sighet (Romênia), até o horror dos campos de extermínio onde deixou pai, mãe e a

\footnotetext{
${ }^{5}$ Aqui foi utilizada a versão italiana Tutti i fiumi portano al mare.
}

irmãzinha, desde sua sobrevivência, como ele a denomina, antes na França, depois em sua volta ao mundo, e, por fim, nos Estados Unidos. Uma sobrevivência durante a qual, graças também à tarefa de jornalista e professor, assiste aos grandes acontecimentos dos últimos 30 anos, conhece personagens de relevo, chefes de estado, e tem amigos como Primo Levi e François Mauriac.

Autor de numerosos romances publicados em vários países de mundo e em diversas línguas, defensor das vítimas, dos sobreviventes, dos oprimidos, o prêmio Nobel pela Paz nos demonstra que, mesmo sem nunca esquecer, com feridas que jamais cicatrizarão, embora continuando a lutar entre dúvida e fé, ainda se pode olhar para frente, ainda se pode acreditar na amizade, no amor, na paz. Numa palavra: no homem.

Por isso, o livro é a história de uma vida dedicada à memória e à esperança, apesar de tudo e, após 70 anos, a lembrança parece tremendamente atual. São flashes de uma intimidade arrasadora. Há uma irmãzinha que ele não consegue esquecer, e que perdeu junto com os pais mortos em Auschwitz. E, todavia, não há agressividade, raiva, violência: para quem quer ouvir, há doçura, tristeza profunda, humor e auto-ironia, por vezes, e, sobretudo, esperança de poder intervir, ainda, contra a indiferença.

A seguir, publicará o segundo volume de suas memórias, And the sea is never full: memoirs ${ }^{6}$, onde promete tornar-se militante, propõe-se a ensinar e compartilhar sua experiência, revelar e aliviar a solidão das vítimas. Esses são os desafios que Elie Wiesel se propõe: os espaços marcados pela guerra, racismo, ditadura e segregação determinarão a geografia de seu empenho e, dias após dia, sua própria história. São palestras, declarações e intervenções, para o escritor a palavra se torna uma arma com a qual combater também aqueles "intelectuais da inquisição" que falam em "dividendos de Auschwitz" ou na "indústria do Holocausto". Ma a solidão e a dor são sempre suas companheiras, apesar do carinho de seus alunos de Nova lorque, de

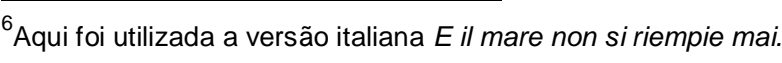


Boston e Yale. De fato, como poderia o adolescente de Sighet, salvo por um milagre, esquecer e renunciar a seu papel de testemunha, defensor dos direitos de todos os homens?

Dando continuidade à sua autobiografia, Elie Wiesel demonstra ser a incansável testemunha da violência dos homens sobre seus semelhantes, e reitera seu desejo de paz entre os homens no mundo inteiro.Aqui assistimos ao tocante testemunho de um garoto oriundo de Sighet que vê desaparecer pouco a pouco seu mundo e com ele as coisas nas quais acreditava, que conhece a deportação e o terror de estar no mundo, que é acolhido na França, que se apaixona pela história do nascimento de um estadoressarcimento pelas injustiças milenares sofridas por seu povo, Israel. Após tornar-se jornalista e professor, ele dá volta ao mundo para testemunhar o sexto sentido hebraico, a memória. Participa dos temores e dos medos e da ansiedade que aquele estado possa desaparecer por causa das inúmeras guerras nas quais está envolvido.

Escreve muito, alinhava também um processo virtual contra Deus em sua única peça teatral II processo di Shamgorod $(1988)^{7}$, na qual o escritor volta ao tema do incompreensível comportamento de Deus quando da chacina dos judeus em 1649, no vilarejo polonês de Shamgorod.

Só Satanás se apresenta ao processo na qualidade de advogado. No Processo, não há ninguém defendendo Deus. A ação ocorre quando alguns judeus se reúnem para celebrar o Purim (Carnaval hebraico). Comenta-se na vila a respeito de outro terrível Progrom se aproximando, como o que aconteceu alguns anos antes. Parece que nada vai impedir essa nova desgraça e, por isso, Deus é acusado de não intervir a favor dos crentes, deixando de exercer sua Justiça e Misericórdia.

Após o Nobel, Wiesel se preocupa com a sorte dos refusnik russos que se recusam a servir o exército e dos judeus aos quais não era permitido fazer alijah no regime soviético, isto é, voltar à terra de Israel, numa acepção política. É a história deste

\footnotetext{
${ }^{7}$ The trial of God, no original de 1979.
}

século e, com ele, a história da passagem pela "porta da esperança".

\section{Ampliando as perspectivas}

Como foi possível constatar, ao lado da "literatura do Lager" escrita por sobreviventes, existe também a tentativa de ampliar a perspectiva para alcançar outros eventos dramáticos e outros genocídios ocorridos e ocorrendo, outras "limpezas étnicas", mas o ponto de partida não pode ser outro, um ponto irrenunciável e fundador para toda a Europa e os europeus, como alerta Zampieri (p. 78). Poderíamos acrescentar, para a África e os africanos também, entre outros. Do massacre dos armênios (1915-1917), do genocídio cambojano de Pol Pot, do Chile de Pinochet à Ruanda dos ferozes genocídios tribais, desde a Bósnia-Erzegovina ao Kossovo das fossas comuns e da limpeza étnica, detenções, torturas e morte de oponentes pontuaram a história do século XX. Conforme Martelli, poderíamos dizer que, particularmente, o nazismo, "em seus métodos de extermínio ou na distorção orwelliana da língua fez escola e proselitismo, mesmo depois de seu desaparecimento, (amargas, severas reflexões deveriam ser feitas também a respeito dos sistemas carcerários de Guantánamo e Abu Ghraib" $\left(\right.$ MARTELLI, 2005) ${ }^{8}$. O ponto, pois, só pode ser a literatura do Lager.

Justamente por isso, o percurso histórico e humano é aquele que levou o sobrevivente a tornarse, antes de tudo, testemunha, e depois, a testemunha, a tornar-se escritor e memorialista. É nisso que gostaria de insistir, porque, nessa trajetória, é obvio, o que se perde, de alguma forma, é a intimidade da memória individual, mas o que se adquire é a dimensão de uma escritura ética, isto é, capaz de questionar os grandes valores existenciais do homem, suas escolhas e, de alguma forma, sua

\footnotetext{
8 "nei metodi sterminazionisti sia nella distorsione orwelliana della lingua, abbia fatto scuola e proseliti anche dopo la sua scomparsa (amare, severe riflessioni andrebbero qui svolte anche sui sistemi carcerari di Guantanamo e Abu Ghraib)."
} 
própria natureza humana. $^{9}$ (ZAMPIERI, 2004, p. 72, grifos do autor)

Enzo Collotti, um dos mais lúcidos historiadores da contemporaneidade, analisa as premissas materiais do extermínio, a fase da guetização, resumindo de maneira muito eficaz aquilo que pode ser considerado sua essência. O profundo horror que envolve todo o evento do genocídio continua levantando questionamentos também ao redor do embrutecimento e da educação totalitária que tornaram possível o extermínio com a ajuda (consciente ou não) do povo alemão. A problemática levantada por Hannah Arendt na época do processo Eichmann e traduzida como "a banalidade do mal" continua mais viva e aberta do que nunca. É preciso, pois, enfatizar a indissociabilidade de crimes dessa dimensão da natureza do regime político do totalitarismo nazista cujo primeiro passo foi a despersonalização das vítimas e a normalização/normatização burocrática dos algozes, fundada no mais amplo desprezo pela vida humana (COLLOTTI, 1995, p. 61).

Zampieri cita ainda uma fase final da literatura do Lager, os anos 90, quando ocorre algo extraordinário, porque, embora a produção literária dos anos 60, 70 e 80 seja muito abundante, nos anos 90 assistimos a um fenômeno intrigante, praticamente imprevisível, pelo menos porque estamos à distância de décadas dos eventos. Aqui podemos capitular obras de mulheres sobreviventes como as de Edith Bruck, Etty Hillesum, Janina Bauman, Ida Fink, Ruth Klüger, Elisa Springer, Inge Auerbacher entre muitas outras que, além do testemunho, publicaram narrativa ficcional sobre o tema, sobre a história da Shoah e sobre a história hebraica.

As memórias de Inge Auerbacher ( $/$ am a star. child of the Holocaust), destinadas a um público jovem (ela tinha 7 anos quando foi aprisionada no

\footnotetext{
9 "Il percorso storico e umano, allora, è quello che ha portato il sopravvissuto a farsi innanzitutto testimone, e poi il testimone a farsi scrittore.È su questo che io vorrei insistere, perché in questa traiettoria, è ovvio, ciò che si perde, in qualche maniera, è l'intimità del ricordo individuale, però ciò che si acquisisce è la dimensione di una scrittura etica, capace cioè di mettere in questione i grandi valori esistenziali dell'uomo, le sue scelte, in qualche maniera la sua stessa natura umana."
}

campo de concentração, e a estrela de que fala o título é a estrela amarela de David que os prisioneiros tinham que usar obrigatoriamente como marca de sua condição judaica), na verdade significam mais do que memória, elas são um aviso, direcionado a nós, adultos, para que a infância e a inocência que nela permanecem não sejam corrompidas pela dor, pela violência e pela morte. Inge deseja que toda criança possa crescer em paz, sem nunca conhecer a fome e a injustiça.

No entanto, embora a literatura de testemunho dos sobreviventes seja extremamente relevante, começam a surgir obras de outras perspectivas e que podem ser incluídas na categoria "literatura do Lager", porque é preciso "ensinar Auschwitz", como quer o Prof. Zampieri. Também o historiador George Bensoussan indaga com rigor e lucidez não apenas a dinâmica da Shoah como fato histórico, mas também o modo pelo qual a civilização ocidental administrou e administra a memória do evento - uma memória muitas vezes mistificadora e conciliadora que tende a atenuar o alcance traumático do acontecimento - ao invés de questionar-se sobre suas próprias responsabilidades.

Para evitar os meandros da retórica, de acordo com Bensoussan, é preciso começar a levar em conta as questões políticas e educacionais que essa história levanta, iniciando pelo problema do ensino às gerações presentes e futuras, adotando uma abordagem crítica que até poderia parecer impopular. Bensoussan se pergunta e nos pergunta: a Shoah constituiu uma aberração imprevisível e única ao longo da história, ou uma inevitável evolução da própria civilização ocidental? Por isso, ele alerta:

Chegará o dia no qual todos os contemporâneos do desastre terão desaparecidos por completo, um dia em que essa saída da História poderá favorecer a mitificação ou a banalização do fato, de resto já em andamento, que consiste em não distinguir e não reconhecer sua especificidade. [...]. Enfatizando a ruptura que a Shoah representou na história da civilização, o trabalho histórico talvez será capaz de salvaguardar a memória particular da catástrofe. Por isso, o dever de História deve prevalecer sobre o dever da memória. É tarefa da História determinar se essa 
barbáriefoi apenas um desvio ou, pelo contrário, a expressão de uma potencialidade inata em nossa civilização. Esclarecendo o sentido daquilo que aconteceu antes e daquilo que veio depois da Shoah, sem nivelamentos nem generalizações, sublinhando a absoluta singularidade de cada acontecimento, a História poderá evitar a relativização do assassinato em massa. A compaixão e a piedade pelas vítimas não serão suficientes, por si sós, para proteger a memória do extermínio. [...] Nas litanias das tragédias de uma época carente de ideais, a história da Shoah poderá correr o risco de fornecer apenas uma razão entre outras para deplorar, de forma retórica, a barbárie do século que termina. ${ }^{10}$ (BENSOUSSAN, 1998, p. 102)

Com frequência, quando celebramos a memória do extermínio dos judeus e não judeus, perpetrado pelos nazistas, procuramos concluir com um "nunca mais" perigosamente suspenso e impreciso. A imensa barbárie da Shoah nos deixa sem palavras, reduz nossa expressão a um mero vocativo e deixa de explicar com clareza o que aconteceu. Pelo contrário, o que a história necessita não é um estéril dever de memória, mas o dever de um rigor histórico que ensine, a quem ainda não sabe, como e quando essa atrocidade foi consumada. Como afirma Hannah Arendt, o genocídio judaico "foi um crime contra a humanidade, [embora] perpetrado no corpo do povo hebraico"11 (ARENDT, 1963, p. 275, meu grifo).

Disso deriva a atualidade e a pertinência do tema, pois a unicidade da Shoah deve ser protegida de comparações, muitas vezes demasiado soltas, com outros tipos de extermínio que ocorrem no nosso

\footnotetext{
10 "Verrà in giorno, quando i contemporanei del disastro saranno tutti scomparsi, in cui questa uscita dalla Storia favorirà la mitizzazione, vale a dire l'ulteriore banalizzazione del fatto, del resto già avviata, che consiste nel non distinguerne la specificità. [...] Sottolineando quale rottura abbia rappresentato lo sterminio nella storia della civilizzazione, il lavoro storico forse salvaguarderà il ricordo particolare di questa catastrofe. Per questo il dovere di Storia deve prevalere sul dovere di Memoria. Spetta all'analisi storica determinare se questa barbarie è stata solo uno sbandamento, o invece, l'espressione di una potenzialità insita nella nostra civiltà. Chiarendo il senso di ciò che è venuto prima e di ciò che è venuto dopo la shoah, senza né livellamenti né generalizzazioni e mettendo in rilievo l'assoluta singolarità di ogni avvenimento, la Storia eviterà la relativizzazione dell'assassinio di massa. [...] La compassione e la pietà per le vittime non basteranno, da sole, a salvaguardare la memoria del disastro. Nella litania delle tragedie di una epoca senza ideali, la storia della shoah non fornirà più, allora, che una ragione tra le altre di deplorare, in maniera retorica, la barbarie del secolo che si conclude."

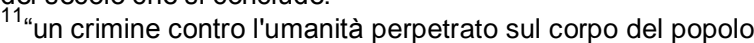
ebraico."
}

presente. Como muitos estudos já demonstraram, a abertura dos portões de Auschwitz não significa o fim dos campos. O campo nasce antes do nazismo talvez em Cuba, em 1896, por obra dos espanhóis que queriam reprimir a insurreição dos colonos, e persiste depois. Como sustenta Giorgio Agamben em Homo Sacer (1995), trata-se de uma anomalia que pertence ao passado, porém, de alguma maneira, é a matriz escondida, o nomos do espaço político no qual ainda vivemos. Ele nasce do estado de exceção, isto é, da suspensão da constituição e dos direitos fundamentais, e o realiza através da normatização. Também em nossos regimes democráticos, que recorrem àquele espaço envolto em arame farpado toda vez que a emergência o exige, quer se trate de terrorismo ou de imigrados. Isso para dizer que a unicidade da Shoah permanece, mas o campo pode voltar, aliás, já voltou. Gostaria que se celebrasse o Dia da Memória com um olhar sobre os macacões cor de laranja de Guantánamo. ${ }^{12}$ (DOMINIJANNI, 2005).

Numa perspectiva histórica e política, Traverso sustenta que o nazismo tornou-se "uma forma de modernismo reacionário" e, por isso, ele é produto da história européia:

A singularidade histórica do nazismo não pode, de fato, ser separada de seu pertencimento ao código genético do mundo ocidental, uma vez que tudo isso, embora não faça com que Auschwitz desvele a essência profunda do Ocidente, designa certamente o nazismo, para além de qualquer determinismo mecânico, como um de seus produtos possíveis e, neste sentido, como um de seus filhos legítimos. ${ }^{13}$ (TRAVERSO, 2002, p.180)

\footnotetext{
12 "che va salvaguardata da troppo disinvolti paragoni con altre forme di sterminio operanti nel nostro presente. In bilico fra questi due passaggi, credo che si possa e si debba dire questo. Come molti studi hanno ormai dimostrato, l'apertura dei cancelli di Auschwitz non significa la fine dei campi. II campo nasce prima del nazismo - forse a Cuba nel 1896, opera degli spagnoli per reprimere l'insurrezione dei coloni - e permane dopo; non è, scrive Giorgio Agamben in Homo Sacer, "un'anomalia appartenente al passato, ma, in qualche modo, la matrice nascosta, il nomos dello spazio politico in cui ancora viviamo". Esso nasce dallo stato di eccezione, ovvero dalla sospensione della costituzione e dei diritti fondamentali, e lo realizza normalizzandolo: anche nei nostri regimi democratici, che ricorrono a quello spazio recintato ogni volta che "l'emergenza" lo richiede, che si tratti di terrorismo o di immigrati. Questo per dire che l'unicità della Shoah resta, ma il campo può tornare, anzi è già tornato. Vorrei che si celebrasse la giornata della memoria con un occhio alle tute arancione di Guantanamo."

13 "La singolarità storica del nazismo non può infatti essere strappata dalla sua appartenenza al codice genetico del mondo occidentale, tutto ciò non fa di Auschwitz il disvelamento
} 
Observando por esse ângulo, então, a unicidade do genocídio dos judeus não se constitui apenas como evento sem precedentes, mas como "a síntese única" de um vasto conjunto de formas de opressão e de extermínio já experimentadas, cada uma separadamente das outras, ao longo da história moderna (idem, p. 181). De acordo com Traverso, existe uma continuidade histórica que faz da Europa liberal um laboratório das violências do séc. XX, e faz de Auschwitz um produto autêntico da civilização ocidental (p. 183). Por isso, pelo menos duas razões justificam a imperiosa necessidade de nunca esquecer a Shoah: 1) a pergunta que não quer calar sobre os motivos de tanto horror e 2) o empenho para que Auschwitz não se repita. Como enfatiza Michele Martelli:

Dizer o que foi dito por Raul Hilberg, Hannah Arendt, Sigmunt Bauman [entre outros], [...] que a Shoah é o produto extremo da modernidade (o entrelaçamento de impiedosa ditadura totalitária, anti-semitismo, racionalidade instrumental técnico-científica, hierarquismo e funcionalismo burocrático) é uma resposta plausível no plano descritivo e sócio-histórico, porém "a interpretação não atende ao aspecto histórico-moral e axiológico onde os problemas já são de ordem teológica e filosófica". ${ }^{14}$ (MARTELLI, 2005, meu grifo)

\section{Considerações finais}

Dentro deste curto espaço, procuramos traçar um resumido panorama da "literatura do Lager" (poder-se-ia dizer uma categoria literária do testemunho) até o presente. Como vimos, hoje ela não se limita à escritura de sobreviventes, uma vez que já existe uma abundante literatura crítica sobre o tema. Por outro lado, tanto a segunda como a terceira

dell'essenza profonda dell'Occidente, ma designa il nazismo, al di fuori di ogni determinismo meccanico, come uno dei suoi prodotti possibili e, in questo senso, come uno dei suoi figli legittimi."

14"Dire, come è stato detto (Raul Hilberg, Hannah Arendt, Sigmunt Baumann, ecc.) che la Shoah è il prodotto estremo della modernità (intreccio di spietata dittatura totalitaria, antisemitismo, razionalità strumentale tecno-scientifica, gerarchismo e funzionalismo burocratico), è una risposta plausibile sul piano descrittivo, storico-sociologico, "ma non risolutiva su quello storico-morale, assiologico, dove i problemi sono teologici e filosofici." geração dos sobreviventes também decidiram falar, desta vez pela ficção.

Na tese intitulada Memoria indiretta del Lager negli scrittori della seconda e terza generazione (2003), Elena Pelloni aborda o extermínio judaico vivenciado indiretamente pela geração dos filhos e netos dos sobreviventes, questionando, sobretudo, se ainda é possível fazer literatura de Auschwitz, qual o conteúdo, qual a forma e o estilo a serem adotados nessas obras, o que nos leva a repensar a espinhosa temática a partir dessa nova perspectiva pósmoderna. Trata-se de uma literatura que relaciona e, ao mesmo tempo, separa os escritores que se dedicaram a ela, tanto do ponto de vista literário e memorialista, quanto do ponto de vista histórico, filosófico, ético e político.

Pelloni reflete sobre os acontecimentos do Lager afirmando que estes não podem e não devem ser arquivados como meros "fatos históricos", pelo contrário, devem permanecer como fatos humanos. A memória e a análise desses fatos devem continuar a interessar e envolver as gerações posteriores descendentes daqueles sobreviventes que vivenciaram in loco $e$ in mente os campos do extermínio. Trata-se de uma questão irrenunciável de responsabilidade moral, social, ética e histórica.

Outros aspectos abordados pela tese de Pelloni referem-se ao conteúdo das obras de memória indireta, onde se observam "estratégias de reticência", já presentes nas narrativas dos sobreviventes e utilizadas novamente pelos escritores de memória indireta, porém com outros objetivos e de outras formas.

Aquilo que não é dito pelo sobrevivente encerra acepções de ordem mais psicológica do que estratégica, sustenta Pelloni, uma vez que "o não dito" se justifica, muitas vezes, pela exigência de preservar um certo equilíbrio emocional, uma defesa contra a avalanche das lembranças dolorosas e também pelo temor de que não se acredite nos autores das memórias.

Para o autor contemporâneo, pelo contrário, o não dito representa uma autêntica estratégia narratológica, enquanto a reticência na descrição da 
brutalidade descrita é substituída pela violência da ficção que, de alguma forma, transfere noutro contexto a tragédia e suas consequências indiretas da experiência do campo de concentração.

Quanto ao aspecto da forma, nos romances analisados por Pelloni, a narrativa se realiza em primeira ou terceira pessoa de um ou de mais personagens. Desaparecem as reflexões explícitas e/ou ontológicas, uma vez que tudo é comunicado através dos tempos e dos modos da história dos protagonistas. Quanto ao tempo da ação, Pelloni observa uma característica comum nos romances analisados, isto é, eles não refletem mais aquela ordem cronológica própria da maioria das narrativas da literatura memorialista, geralmente caracterizada pelos relatos que organizam três espaços temporais: o tempo antes da deportação, o tempo da guerra e da experiência do Lager e, por fim, o tempo da volta à vida.

$\mathrm{Na}$ narrativa ficcional contemporânea, os tempos narrativos se sobrepõem constantemente, muitas vezes entrelaçando presente, passado e novamente presente, enquanto a linguagem $e$ as imagens se tornam, sobretudo, simbólicas.

Por essa razão, Alain Parrau, citado por Pelloni, ${ }^{15}$ sustenta que a linguagem da literatura do campo de extermínio deve expressar o indizível e, nessa representação, fazer dele também o espaço para o dizível, para o imaginável e o inimaginável. Nesse aparente contraste, a linguagem deve acabar traduzindo seu antagonismo para uma verdade superior. E, quanto ao leitor, ele deve perceber e compreender toda a dramaticidade da ação pela intuição, mesmo que jamais tenha vivenciado essa experiência extrema, isto é, ele deve transpor as fronteiras da narrativa.

Como bem afirma Zampieri, a literatura narra a nossa existência que se torna história. Cada evento, cada indivíduo, cada sentimento, retirado da particularidade quotidiana de quem o vivenciou, tornase um discurso comum, em palavra de todos porque a todos pertence, porque cada um tem o direito de apropriar-se daquelas palavras, revivê-las como se as

\footnotetext{
${ }^{15}$ Écrire les camps. Paris: Belin, 1995, p.298.
}

tivesse vivenciado realmente, experimentar de novo aquelas sensações como se lhes tivessem pertencido desde o começo:

A literatura possui essa força extraordinária, a de tornar comum o que é particular, de colocar à disposição de todos aquilo que, de outra forma, permaneceria como experiência individual. Mas isso não é tudo. A literatura é a nossa memória. Não apenas porque ela lembra, além dos tempos, aquilo que nós não poderíamos recordar, aquilo que, quando os protagonistas tiverem desaparecido, não saberíamos mais como tornar verdadeiro, mas, sobretudo, porque ela nos oferece uma memória carregada de saber, de paixões, de emoções, não um arquivo de dados organizadamente reunidos, mas uma paisagem vária e complexa, onde os monumentos se seguem e os traços daquilo que foi, ora grandes ora pequenos, ora de peso indestrutível, ora de levezas inconsistentes, estão ali ao dispor de quem deseje empreender esse caminho. ${ }^{16}$ (ZAMPIERI, 2003)

Quando a última testemunha do extermínio terá desaparecido, quando aquela lembrança não será mais confiada à voz viva dos protagonistas, teremos aprendido a lição e seremos capazes de nos defendermos dos desvios da memória? O risco de esquecer é tão grande que precisaríamos de um aniversário de Auschwitz todos os dias. Até quando o dia 27 de janeiro ainda será capaz de trazer testemunhas vivas da grande tragédia? Muito em breve só a literatura do lager, a memória que se fez literatura, muito mais que comemorações e flores, e discursos e lágrimas, e visitas comovidas aos campos de extermínio, será capaz de manter viva a memória pessoal e coletiva de uma história que precisa ser discutida, analisada e divulgada.

No prefácio do livro-testamento da sobrevivente austríaca Elisa Springer (1997), lemos: "Hoje, mais do que nunca, é preciso que os jovens

\footnotetext{
${ }^{16}$ "La letteratura ha questa forza straordinaria, di rendere comune quel che è privato, di mettere a disposizione di tutti quel che altrimenti resterebbe muta esperienza individuale. Ma non è tutto. La letteratura è la nostra memoria. Non soltanto perché essa ricorda al di là dei tempi quel che noi non potremmo ricordare, quel che, venuti meno i protagonisti, non sapremmo più come rendere vero, ma soprattutto perché essa ci offre una memoria carica di sapienza, di passioni, di emozioni, non un archivio di dati ordinatamente raccolti, ma un paesaggio vario e complesso, ove i monumenti si susseguono e le tracce di quel che è stato, ora grandi, ora piccole, ora di indistruttibile pesantezza, ora di inconsistenti leggerezze, sono lì a disposizione di chi voglia intraprendere questo cammino."
} 
saibam, compreendam e entendam. É essa a única forma de termos a esperança de que aquele indizível horror não se repita, é a única maniera de sairmos da escuridão. E então, se o meu testemunho, a minha narrativa de sobrevivente dos campos de extermínio, a minha presença no coração de quem entende a piedade, servir para fazer crescer a compreensão e o amor, eu também, então, poderei pensar que na vida, tudo aquilo que foi absurdo e trágico, poderá ter servido como resgate pelo sacrifício de tantos inocentes, como amor e consolo para quem está só; terá servido para construir um mundo melhor, sem ódio e sem barreiras. Um mundo no qual homens livres, capazes e não escravos da própria intolerância, derrubando os confins de seu próprio egoísmo, terão devolvido à vida, e a todos os demais homens, o significado da palavra liberdade". ${ }^{17}$

Trata-se de uma imperiosa denúncia que convoca a todos para a autêntica conscientização daquilo que foi e que não poderá voltar a acontecer. O neonazismo e o anti-semitismo, o negacionismo e o extremismo político representam ameaças que não podem ser ignoradas, elas estão entre nós, inclusive em nosso próprio país. ${ }^{18}$

\section{Referências}

AGAMBEN, Giorgio. Homo Sacer: il potere sovrano e la nuda vita. Torino: Einaudi, 1995.

ANTELME, Robert. A espécie humana. Rio de Janeiro: Record, 2013.


capiscano e comprendano. È l'unico modo per sperare che quell'indicibile orrore non si ripeta, è l'unico modo per farci uscire dall'oscurità. E allora, se la mia testimonianza, il mio racconto di sopravvissuta ai campi di sterminio, la mia presenza nel cuore di chi comprende la pietà, serve a far crescere comprensione e amore, anch'io allora, potrò pensare che, nella vita, tutto ciò che è stato assurdo e tremendo, potrà essere servito come riscatto per il sacrificio di tanti innocenti, amore e consolazione verso chi è solo, sarà servito per costruire un mondo migliore senza odio, né barriere. Un mondo in cui, uomini liberi, capaci e non schiavi della propria intolleranza, abbattendo i confini del proprio egoismo avranno restituito, alla vita e a tutti gli altri uomini, il significato della parola libertà". II silenzio dei vivi: all'ombra di Auschwitz un racconto di morte e resurrezione. Venezia: Marsilio, 1997.

${ }^{18}$ Ver: MILMAN, Luis; VIZENTINI, Paulo Gilberto. Neonazismo, negacionismo e extremismo político. Porto Alegre: Editora da UFRGS, 2007.
}

ARENDT, Hannah. La banalità del male: Eichmann a Gerusalemme. Trad. P. Bernardini. Milano: Feltrinelli, 1963.

AUERBACHER, Inge. I am a star: child of the Holocaust. USA: Prentice-Hall Books, 1993.

BENSOUSSAN, George. Auschwitz en héritage? D`un bon usage de la mémoire. Paris: Mille et Une Nuits, 1998.

BROCCHIERI, Maria Teresa Fumagalli Beonio. L`alibi del deicidio. Disponível em: http://rete.toscana.it.sett/lefp/pubblicazioni/allegati/edu 05 op.pdf. Acesso em out. 2006.

BRUCK, Edith. Signora Auschwitz: il dono della parola. Venezia: Marsilio, 1999.

COLLOTTI, Enzo. La soluzione finale: lo sterminio degli ebrei. Roma: Newton Compton, 1995.

DOMINIJANNI, Ida. Per il presente. Le relazioni operative della memoria. Disponível em: http//www.golemindispensabile.it. 2005. Acesso em out. 2006.

LEVI, Primo. Se questo è un uomo. Torino: Einaudi, 1958.

MARTELLI, Michele. La Shoah tra memoria e oblio. Disponível em: http://www.golemindispensabile.it>. 2005. Acesso em out. 2006.

MILLU, Liana. // fumo di Birkenau. Firenze: Giuntina, 1995.

NICOLESCU, Basarab. O manifesto da transdisciplinaridade. 2. ed. Trad. Lucia Pereira de Souza. São Paulo, Triom, 2001.

PELLONI, Elena. Memória indiretta del Lager negli scrittori della seconda e terza generazione. Disponível em: http://www.morasha.it/tesi/index.html. 2003. Acesso em ag. 2007.

ROUSSET, David. L'univers concentrationnaire. Paris: Fayard/Pluriel, 2011.

Les jours de notre mort. Paris: Hachette, 2005.

SEMPRÚN, Jorge. El largo viaje. Barcelona: Tusquets, 2004.

SPRINGER, Elisa. I/ silenzio dei vivi: all'ombra di Auschwitz un racconto di morte e resurrezione. Venezia: Marsilio, 1997.

STEFANI, Piero. L’antigiudaismo: storia di una idea. Bari-Roma: Laterza, 2004.

TRAVERSO, Enzo. La violenza nazista: una geneaologia. Bologna: Il Mulino, 2002.

WIESEL, Elie. A noite. São Paulo: Saraiva, 1958. 
. Il processo di Shamgorod. 4. ed. Trad. Daniel Vogelman. Firenze.La Giuntina, 1988.

Tutti i fiumi portano al mare: memorie. Trad. Vincenzo Accame. Milano: Bompiani, 2002.

E il mare non si riempie mai: memorie. Trad. Nicola Jacchia. Milano: Bompiani, 2003.

ZAMPIERI, Stefano. Scrivere, testimoniare. Disponível em: http://members.tripod.com/littera/scrivere.htm. 2003. Acesso em: 16 set. 2005.

Lager e letteratura. In: Atas del Seminario Figure della Memoria. Firenze, p. 8-12, jan. 2004. Pisa:Edizioni Plus/Università di Pisa, dez. 2004. p. 7381. Disponível em: http://rete.toscana.it.sett/lefp/pubblicazioni/allegati/edu 05op.pdf. Acesso em out. 2006. 